\title{
Effects of in-season uphill sprinting on physical characteristics in semi-professional
} soccer players

\author{
Mykolas Kavaliauskas, ${ }^{1}$ Ross Kilvington, ${ }^{1}$ John Babraj ${ }^{1}$
}

${ }^{1}$ School of Social and Health Sciences, Division of Sport and Exercise Science, Abertay

University, Dundee, UK

Congresses: N/A

Funding: There was no funding

Conflicts of interest: There were no conflicts of interest

Acknowledgements:

Corresponding author:

J. Babraj,

School of Social and Health Sciemces,

Division of Sport and Exercise Science,

Abertay University,

Bell Street,

DD1 1HG, Dundee,

UK

E-mail: j.babraj@abertay.ac.uk 


\begin{abstract}
Aim. Soccer performance is determined by a number of physiological adaptations that can be altered by high intensity training. However, the effectiveness of using an uphill sprint based protocol has not been demonstrated for soccer players. We sought to determine the effectiveness of an in-season uphill sprint training (UST) programme on soccer related physiological outcomes.
\end{abstract}

Methods. 14 male soccer players (age: $22 \pm 8$ years, height: $1.81 \pm 8 \mathrm{~m}$, body mass: $76 \pm 12$ $\mathrm{kg}$ ) underwent testing (5-10-5 agility drill, Yo-Yo Intermittent Recovery Test Level 1, leg and back dynamometry $\& 3 \mathrm{~km}$ time trial) at baseline and after 6 weeks of UST or normal activity. Participants were allocated to a control $(n=7)$ or UST $(n=7)$ group. The UST group took part in twice weekly training consisting of $10 \times 10 \mathrm{sec}$ sprints with 60 s recovery on a $7 \%$ gradient for 6 weeks. The control group maintained normal activity patterns.

Results. $3 \mathrm{~km}$ time trial, strength, agility and Yo-Yo performance were all significantly improved pre to post following 6 weeks of UST (Agility 3\%, $d=1.3$; Strength 10\%, $d=-3.2$; $\mathrm{VO}_{2} \max 3 \%, d=-1.4 ; 3-\mathrm{km}$ TT $\left.4 \%, d=1.3\right)$. In the control group $3 \mathrm{~km}$ time trial, strength, agility and Yo-Yo performance remained unchanged after 6 weeks (Agility $0.1 \%, d=-0.2$; Strength $2 \%, d=0.0 ; \mathrm{VO}_{2} \max -0.1 \%, d=0.0 ; 3-\mathrm{km}$ TT $\left.1.3 \%, d=0.3\right)$.

Conclusion. Therefore in-season short duration UST is an effective way to improve soccer fitness in a time efficient manner.

Key words: High Intensity Training, Soccer, Endurance performance, Strength 


\section{Introduction}

Quantification of physiological demands is complex as it is largely determined by the demands of positional groups, team tactics, opposition strategy and individual match-ups ${ }^{1}$. Players typically cover $10-12 \mathrm{~km}$ at an average intensity of approximately $70 \%$ of maximal oxygen uptake $\left(\mathrm{VO}_{2} \max \right)$ during games, thus relying on the aerobic production of energy ${ }^{2}$. Bishop et al. ${ }^{3}$ suggest that a higher $\mathrm{VO}_{2}$ max in soccer can prolong high-intensity performance, due to the greater contribution of aerobic metabolism during later sprints. Therefore aerobic metabolism becomes important in the second half of soccer games when the total distance covered and the number of high-intensity runs are reduced ${ }^{4} . \mathrm{VO}_{2}$ max has also been associated with successful performance in soccer, with greater $\mathrm{VO}_{2}$ max found in players of more successful clubs and national teams ${ }^{4}$. In addition to the high aerobic demand, the nature of the game requires players to repeatedly perform sprints, turns, tackles and jumps ${ }^{5}$. Therefore a high anaerobic capacity is also required to perform these types of movements ${ }^{2}$.

Training for these diverse physical demands becomes challenging, especially during the inseason because of the high number of competitive fixtures, the need for frequent travel and because technical and tactical sessions are usually prioritised over physical training ${ }^{6}$. Other commitments (e.g., work/study) and accumulated fatigue may also result in a reduced physical capacity and lower performance level of soccer players as the season progresses. A significant decrease in aerobic fitness, from midseason to the end of the season, has been demonstrated in semi-professional male soccer players ${ }^{7}$. In contrast, Magal et al. ${ }^{8}$ have demonstrated a significant improvement in $\mathrm{VO}_{2} \mathrm{max}$ and sprint performance in collegiate male soccer players over the course of the soccer season. Nevertheless, seasonal changes in physiological parameters associated with soccer performance are expected to have an effect on the on-field performance of soccer players. Therefore, players and coaches face a challenge to maintain physical fitness whilst finding the time to enhance the tactical and technical qualities of the athlete.

High-intensity interval training (HIT) is a time-efficient training method defined as brief periods of intense exercise interspersed by a short recovery period ${ }^{9}$. Two weeks of Wingatebased HIT, consisting of 4-6 maximal 30 second sprints against $7.5 \%$ of body weight on a cycle ergometer, have been shown to improve aerobic performance and skeletal muscle oxidative metabolism $^{10}$, whilst 6 weeks of HIT appears to modify vascular function ${ }^{11}$. In soccer players, twice weekly aerobic HIT sessions for eight weeks, involving running on the 
flat, have been shown to improve aerobic capacity, lactate metabolism and running economy which subsequently results in an improved soccer performance ${ }^{4,12}$.

Intensity of exercise is crucial to the magnitude of training adaptation ${ }^{13,14}$. Skeletal muscle adaptation to run training is directly related to the intensity of the running programme, with greater adaptations shown at $>80 \% \mathrm{VO}_{2}$ peak $^{14}$. Likewise cardiorespiratory adaptation is also greater with higher exercise intensity ${ }^{13}$. For sprint training the intensity can be altered via increasing mass (weighted vest, sledge), air resistance (parachute) or gradient (uphill sprinting $)^{15}$. For example, uphill sprinting elicits a greater metabolic and mechanical cost compared to flat sprinting ${ }^{15}$. Despite its good ecological validity ${ }^{16}$ and the use by coaches as a resistance-to-movement training method ${ }^{17}$, there is little evidence of uphill sprinting as a time-efficient training method in soccer players. Acutely, uphill intermittent running produces a higher heart rate and blood lactate accumulation than uphill repeated sprinting in soccer players ${ }^{18}$. However, the effectiveness of a longer uphill sprinting programme during in-season on a range of physical characteristics in soccer players remains unknown.

Therefore, the purpose of this study was to determine whether twice weekly shorter duration uphill sprinting training could elicit improvements in endurance, agility and strength parameters in soccer players. It was hypothesised that 12 sessions of short duration uphill sprinting training would significantly improve performance in endurance, agility and strength.

\section{Materials and methods}

Fourteen male soccer players (age: $22 \pm 8$ years, height: $1.81 \pm 8 \mathrm{~m}$, body mass: $76 \pm 12 \mathrm{~kg}$ ) from the Scottish Junior Football Association were recruited. All players had a minimum of 5 years' experience of training twice weekly and playing once weekly. Subjects were randomly allocated into 2 groups, control (age: $23 \pm 7$ years, height: $1.82 \pm 8 \mathrm{~m}$, body mass: $78 \pm 14 \mathrm{~kg}, \mathrm{n}=7$ ) and uphill sprint training (UST) (age: $22 \pm 8$ years, height: $1.75 \pm 8 \mathrm{~m}$, body mass: $74 \pm 11 \mathrm{~kg}, \mathrm{n}=7$ ). The control group were asked to maintain their current training and playing habits. The UST group maintained the same current training and playing whilst adding an uphill sprint protocol twice weekly. For the duration of the study all participants were requested to follow their normal diet. The study was carried out in the second half of competitive season (i.e. February to April). The study protocol was approved by the institutional Ethics Committee and conducted in accordance with the Declaration of Helsinki. 


\section{Baseline testing}

Subjects carried out the following field tests after performing a standardised warm up, consisting of an aerobic warm-up of jogging for 5 minutes followed by standardised dynamic stretches.

\section{5-10-5 agility test}

Three cones were placed along a line $5 \mathrm{~m}$ apart and the participant straddled the middle cone and on the verbal command "go" he sprinted $5 \mathrm{~m}$ in a pre-determined direction (i.e., once to the right and once to the left) and touched the cone; turned and sprinted $10 \mathrm{~m}$ to the other cone; turned and sprinted back to the middle cone. The total time taken to complete this test was recorded in seconds using a stopwatch. Participants repeated the test twice, with 5 minutes recovery between tests, with the best time reported.

\section{Yo-Yo Intermittent Recovery Test Level 1 (Yo-Yo IR1)}

The participants were given 10 min passive recovery before performing the Yo-Yo Intermittent Recovery Test Level 1 on the football pitch. The test consisted of performing repeated $20-\mathrm{m}$ shuttle runs between the starting line and finish line. Each shuttle was performed at increasing velocities with $10 \mathrm{~s}$ of active recovery between runs until exhaustion. The end of the test was considered when the participants had twice failed to reach the front line in time or felt unable to cover another shuttle at the dictated speed. The total distance covered during the test was recorded and then converted to a predicted $\mathrm{VO}_{2}$ peak using the following equation: $\mathrm{VO}_{2}$ peak $=$ distance covered $* 0.0084+36.4{ }^{19}$.

\section{Laboratory testing}

Participants reported to the laboratory $48 \mathrm{~h}$ after the field tests, having fasted for $4 \mathrm{~h}$ prior to arrival. Upon arrival the participants' body composition was measured using a bioelectrical impedance analyser (Tanita TBF-300 Body Composition Analyser, Tanita Inc, USA). Participants were instructed to void their bladder prior to testing to ensure accurate assessment of body composition. Then the following performance tests were completed:

\section{Leg and back strength}

Participants stood on the dynamometer with a slight knee flexion as described previously ${ }^{20}$ and then pulled as hard as possible. This was repeated on 3 occasions, with the average value recorded.

\section{3-km time-trial}

It has been estimated that $3 \mathrm{~km}$ time trials are run at $95 \%$ of $\mathrm{VO}_{2}$ max and $92 \%$ of the velocity at $\mathrm{VO}_{2} \max ^{21}$ and peak running velocity during an incremental treadmill test is a 
good predictor of endurance performance ${ }^{22}$. Therefore $3 \mathrm{~km}$ time-trial is an accurate measure of endurance performance and in soccer it has been demonstrated that enhanced aerobic endurance improves match performance ${ }^{4}$.

Subjects rested for 5 min prior to performing a self-paced time-trial. The treadmill (H/P/Cosmos Mercury, Germany) was set at $1 \%$ gradient $^{23}$ and participants were given instructions to complete the test in the fastest time possible. The treadmill was set to an initial speed of $8 \mathrm{~km} \cdot \mathrm{h}^{-1}$ and then the participants were free to control their own speed throughout the time-trial via a speed-up/slow down button. However, no visual feedback was given to the participants except for distance completed.

\section{Training protocol}

The 6 week training programme consisted of two outdoor training sessions per week on the days when players were not taking part in their regular training sessions. Training sessions were preceded by the standardised warm-up. Each session involved performing $10 \times 10$ second sprints, on a gradient of $7 \%$, followed by a 60 second recovery period that involved walking back to the start (work-to-rest ratio 1:6). Participants were verbally encouraged to give an "all-out" effort in every sprint.

\section{Post testing}

Five days after the last training session participants repeated the baseline tests in the same order and at the same time of day $( \pm 2 \mathrm{~h})$ to avoid diurnal variations in performance.

\section{Data analysis}

Data are expressed as means \pm standard deviation. Data were checked for skewness and kurtosis and these values did not exceed twice the standard error, therefore the data were deemed to be normally distributed. Due to the small sample size the data were analysed using the methodology proposed by Hopkins ${ }^{24}$ for controlled trials. The significance level was set at $0.05(\mathrm{P}<0.05)$ and the Cohen's $d$ effect size were calculated to quantify the magnitude of difference between groups. Further within group (pre to post) Cohen's d effect size were calculated using Morris and Deshon's equation ${ }^{25}$. Effect sizes were defined as follows: $\mathrm{d}<0.2$ trivial effect, $0.2-0.5$ small effect, $0.6-1.1$ moderate effect and $>1.2$ as a large effect ${ }^{26}$.

\section{Results}

\section{5-10-5 agility test}


There were no significant differences in agility performance in the control group pre to post, but agility was significantly increased in the UST group pre to post (Table 1). The percentage change is significantly greater in the UST group compared to the control group (Table 2).

\section{Leg and back dynamometry}

There were no significant differences in isometric strength in the control group pre to post, but isometric strength was significantly increased in the UST group pre to post (Table 1). The percentage change is significantly greater in the UST group compared to the control group (Table 2).

\section{Yo-Yo Intermittent Recovery Test Level 1}

There were no significant differences in distance covered during the Yo-Yo test in the control group pre to post, but distance covered was significantly increased in the UST group pre to post (Table 1). The percentage change is significantly greater in the UST group compared to the control group (Table 2).

There were no significant differences in calculated $\mathrm{VO}_{2}$ max in the control group pre to post, but $\mathrm{VO}_{2}$ max was significantly increased in the UST group pre to post (Table 1). The percentage change is significantly greater in the UST group compared to the control group (Table 2).

\section{3-km time-trial}

There were no significant differences in time taken to complete the 3-km time-trial in the control group pre to post, but the time taken to complete the 3-km time-trial was significantly decreased in the UST group pre to post (Table 1). The percentage change is significantly greater in the UST group compared to the control group (Table 2).

\section{Discussion}

HIT interventions carried out in soccer players have previously been shown to improve sprint performance and aerobic capacity ${ }^{4,27}$. However, these studies have utilised longer duration sprints, which have been performed on the flat, compared to the uphill sprint protocol of this study. This study demonstrates for the first time that 6 weeks of twice weekly uphill sprinting significantly reduces the time taken to complete a soccer specific agility test, increases estimated $\mathrm{VO}_{2}$ peak and reduces time taken to complete a $3-\mathrm{km}$ time 
trial (Table $1 \& 2$ ). Further, there was also a significant increase in leg and back strength (Table $1 \& 2$ ) after 6 weeks of uphill sprint training.

Time to complete the 5-10-5 agility test was decreased by $3.2 \%$ in the UST group, with a large within and between group effect size (Table $1 \& 2$ ). This improvement may reflect an increased acceleration speed following uphill sprints. It has been demonstrated that HIT involving longer duration sprints increases the acceleration phase and $40 \mathrm{~m}$ sprint performance of soccer players ${ }^{27}$, potentially due to greater anaerobic enzyme activity after HIT $^{28}$. Alternatively improved neuromuscular adaptations may improve agility due to increased electrical activity ${ }^{29}$ and more dispersed synapses ${ }^{30}$ after HIT. These neural adaptations may improve power and work production, via increased motor unit recruitment, resulting in greater strength. Strength can be defined as the integrated response of several muscles contracting maximally during a task ${ }^{31}$.

Agility is the ability to rapidly change direction and speed of movement as a result of a stimulus $^{3}$ and requires rapid force development and high power output, as well as the ability to perform ballistic movements ${ }^{32}$. It can be broken down into the time taken to reach maximum velocity ${ }^{33}$ and is determined by the ability of the athlete to generate anaerobic power $^{34}$. For soccer players, agility has been shown to be a key component of performance ${ }^{33 \text {, }}$ 35 . Typically reaction ability over 5 to $10 \mathrm{~m}$ reflects game performance ${ }^{35}$, allowing a faster change of direction and a faster sprint pace ${ }^{36}$. Meylan et al. ${ }^{37}$ demonstrated that leg strength and power are important contributors to speed when changing direction quickly, with the push off action requiring a high volume of force generated.

Following 6 weeks of uphill sprint training, there was a 10\% increase in leg and back strength, with a large within group effect size and a moderate between group effect size (Table 1 \& 2). Ferley et al. ${ }^{17}$ reported a significant improvement in isokinetic strength of between 3 and 5\% in well-trained distance runners following 12 sessions of uphill (10\% incline) sprint training. Strength improvement is generally associated with muscular hypertrophy or neural adaptations ${ }^{38}$. However, it is unlikely that skeletal muscle hypertrophy has occurred during the relatively short duration of the current training programme. Muscle hypertrophy is normally only detected after 8-12 weeks of resistance training ${ }^{39}$ and we see no change in body mass (data not shown). Likewise, others have reported no change in \% muscle mass in young adults following 8 weeks of uphill running HIT $^{40}$. Therefore it seems likely that the increase in strength is due to neural adaptations rather than hypertrophy and 
importantly for soccer players occurs without any increase in body mass, as extra weight can impair performance ${ }^{2}$.

Uphill sprint training has been shown to increase $\mathrm{VO}_{2}$ peak by approx. $6 \%$ after 8 weeks ${ }^{39}$ and is similar to that reported for cycle based HIT protocols ${ }^{11}$. In the current study we report a $3 \%$ increase in $\mathrm{VO}_{2}$ peak after 6 weeks of uphill sprinting training as assessed by the YoYo IR1 test, with a large within group effect size but a small between group effect size (Table $1 \& 2$ ). Further there was a $4 \%$ decrease in time taken to complete a $3 \mathrm{~km}$ time trial, with a large within group effect size but a small between group effect size (Table $1 \& 2$ ). This suggests a small improvement in aerobic metabolism following 6 weeks of uphill sprinting, which may reflect the length of recovery given. A recent study by Kavaliauskas et al. Has demonstrated that a work to rest ratio of 1:3 produces greater aerobic adaptations compared to $1: 8$ or $1: 12$ work to rest ratios ${ }^{41}$. Ferley et al. ${ }^{17}$ report an $8 \%$ improvement in submaximal endurance performance when running at 60 and $80 \%$ of lactate threshold velocity after 6 weeks of uphill sprint training. It has long been established that intensity of exercise is crucial to the magnitude of training adaptation ${ }^{14}$. Following cycle based HIT, improvements in aerobic metabolism have been shown to be largely regulated via increased mitochondrial density and activity ${ }^{10}$ leading to improved time trial performance. With shorter duration cycle based sprints there is a rightward shift in the blood lactate curve resulting in improved time trial performance ${ }^{41}$. Therefore it seems reasonable to assume similar muscular adaptations are underpinning the improvement in aerobic performance in the current study. In soccer, improvements in aerobic capacity have been shown to increase distance covered and the total number of sprint performed during game play ${ }^{31}$.

\section{Conclusions}

In conclusion, this study demonstrated for the first time that short duration uphill sprint training (consisting of 10 second sprints) completed in addition to usual training improves agility, endurance and strength measures in semi-professional male soccer players. Therefore, coaches and sport scientists can use uphill sprinting as a time-efficient training method, that is easily accesable, to optimise in-season training programmes. Future studies should look at the applicability of this type of training within an elite setting or the effect of sprint duration on performance adaptations. 


\section{REFERENCES}

1. Sporis G, Jukic I, Ostojic SM, Milanovic D.. Fitness profiling in soccer: physical and physiologic characteristics of elite players. J Strength Cond Res. 2009; 23:1947-53

2. Stolen, T., Chamari, K., Castagna, C., Wisloff, U. Physiology of soccer. Sports Med. 2005; 35: 501-536.

3. Bishop, D., Girard, O. Mendez-Villanueva, A. Repeated sprint ability - part 2. Sports Med 2011; 41: 741-756.

4. Helgerud, J., Enen, U., Wilsoff, U. and Hoff, J. Aerobic endurance training improves soccer performance. Medicine and Science in Sports and Exercise 2001; 33: 1925-1931.

5. Mohr, M., Krustrup, P. \& Bangsbo, J. Match performance of high standard soccer players with special reference to development of fatigue. Journal of Sports Science 2003; 21: 519528.

6. Morgans R, Orme P, Anderson L, Drust B, Morton JP. An intensive winter fixture schedule induces a transient fall in salivary $\operatorname{IgA}$ in english premier league soccer players. Res Sports Med. 2014; 22:346-54

7. Caldwell BP, Peters DM. Seasonal variation in physiological fitness of a semiprofessional soccer team. J Strength Cond Res. 2009; 23: 1370-7.

8. Magal M, Smith RT, Dyer JJ, Hoffman JR. Seasonal variation in physical performancerelated variables in male NCAA Division III soccer players. J Strength Cond Res. 2009; 23: 2555-9.

9. Glaister, M. Multiple sprint work: physiological responses, mechanisms of fatigue and the influence of aerobic fitness. Sports Medicine. 2005; 35: 757-777.

10. Burgomaster, K.A., Hughes, S., Heigenhauser, G., Bradwell, S. and Gibala, M. Six sessions of sprint interval training increases muscle oxidative potential and cycle endurance capacity in humans. Journal of Applied Physiology. 2005; 98: 1985-1990.

11. Rakobowchuk M, Tanguay S, Burgomaster KA, Howarth KR, Gibala MJ, MacDonald MJ. Sprint interval and traditional endurance training induce similar improvements in peripheral arterial stiffness and flow-mediated dilation in healthy humans. Am J Physiol Regul Integr Comp Physiol. 2008; 295: R236-42.

12. Impellizzeri, F.M., Marcora, S., Castagna, C., Reilly, T., Sassi, A. and Rampinini, E. Physiological and performance effects of generic versus specific aerobic training in soccer players. International Journal of Sports Medicine. 2006; 27: 483-492. 
13. Wenger HA, Bell GJ. The interactions of intensity, frequency and duration of exercise training in altering cardiorespiratory fitness. Sports Med. 1986; 3: 346-56.

14. Dudley, G. A., Abraham, W. M.l and Terjung, R. L. Influence of exercise intensity and duration on biochemical adaptations in skeletal muscle. Journal of Applied Physiology. 1982; 53: 844-850.

15. di Prampero PE, Fusi S, Sepulcri L, Morin JB, Belli A, Antonutto G. Sprint running: a new energetic approach. J Exp Biol. 2008; 208: 2809-2816

16. Padulo J, Powell D, Milia R, Ardigò LP. A paradigm of uphill running. PLoS One 2013; 10; 8(7): e69006.

17. Ferley DD, Osborn RW, Vukovich MD. The effects of incline and level-grade highintensity interval treadmill training on running economy and muscle power in well-trained distance runners. J Strength Cond Res. 28(5):1298-309.

18. Ibba G, Pizzolato F, Di Michele R, Scorcu M, Attene G, Paradisis G, Anon P, Chamari K, Padulo J. (2014). Uphill sprint vs. intermittent running in young soccer players: acute physiological responses. Sport Sci Health 2014; 10: 61-66.

19. Bangsbo J, Iaia FM, Krustrup P. The Yo-Yo intermittent recovery test : a useful tool for evaluation of physical performance in intermittent sports. Sports Med. 2008; 38: 37-51.

20. Coldwells A, Atkinson G, Reilly T. Sources of variation in back and leg dynamometry. Ergonomics. 1994; 37: 79-86.

21. Grant S, Craig I, Wilson J, Aitchison T. The relationship between $3 \mathrm{~km}$ running performance and selected physiological variables. J Sports Sci. 1997; 15: 403-10.

22. Noakes T.D., Myburgh K.H. \& Schall R. Peak treadmill running velocity during the $\mathrm{VO}_{2}$ max test predicts running performance. Journal of Sports Sciences 1990; 8: 35-45

23. Jones AM, Doust JH. A $1 \%$ treadmill grade most accurately reflects the energetic cost of outdoor running. J Sports Sci. 1996; 14: 321-7.

24. Hopkins, W.G. A spreadsheet for analysis of straightforward controlled trials. Journal of Sports Science. 2003; 7.

25. Morris SB, DeShon RP. Combining effect size estimates in meta-analysis with repeated measures and independent-groups designs. Psychological Methods 2002; 7: 105-125.

26. Cohen, J. Statistical power analysis for the behavioural sciences (2nd ed). 1988; New Jersey: Lawrence Erlbaum.

27. Dupont, G., Akakpo, K. and Berthoin, S. The effect of in season high intensity interval training in soccer players. Journal of Strength and Conditioning research. 2004; 18: 584-589. 
28. Ross, A. and Leveritt, M. Long term metabolic and skeletal muscle adaptations to shortsprint training: implications for sprint training and tapering. Sports Medicine. 2001; 31: 1063-1082.

29. Smith AE, Moon JR, Kendall KL, Graef JL, Lockwood CM, Walter AA, Beck TW, Cramer JT, Stout JR. The effects of beta-alanine supplementation and high-intensity interval training on neuromuscular fatigue and muscle function. Eur J Appl Physiol. 2009; 105: 35763

30. Deschenes MR, Maresh CM, Crivello JF, Armstrong LE, Kraemer WJ, Covault J. The effects of exercise training of different intensities on neuromuscular junction morphology. $\mathrm{J}$ Neurocytol. 1993; 22: 603-15.

31. Hoff J, Helgerud J. Endurance and strength training for soccer players: physiological considerations. Sports Med. 2004; 34: 165-80.

32. Thomas, K., French, D. and Hayes, P.R. The effects of two plyometric training techniques on muscular power and agility in youth soccer players. Journal of Strength and Conditioning research. 2009; 23: 332-335.

33. Little T, Williams AG. Specificity of acceleration, maximum speed, and agility in professional soccer players. J Strength Cond Res. 2005; 19: 76-8.

34. Haj-Sassi R, Dardouri W, Gharbi Z, Chaouachi A, Mansour H, Rabhi A, Mahfoudhi ME. Reliability and validity of a new repeated agility test as a measure of anaerobic and explosive power. J Strength Cond Res. 2011; 25: 472-80.

35. Jovanovic M, Sporis G, Omrcen D, Fiorentini F. Effects of speed, agility, quickness training method on power performance in elite soccer players. J Strength Cond Res. 2011; 25: $1285-92$.

36. Kutlu, M., Yapici, H., Yoncalik, O. and Celik, S. Comparison of a new test for agility and skill in soccer with other agility tests. Journal of Human Kinetics. 2012; 33: 143-150. 37. Meylan CM, Cronin J, Oliver JL, Hopkins WG, Pinder S. Contribution of vertical strength and power to sprint performance in young male athletes. Int J Sports Med. 2014; 35:749-54.

38. Seynnes OR, de Boer M, Narici MV. Early skeletal muscle hypertrophy and architectural changes in response to high-intensity resistance training. J Appl Physiol 2007; 102: 368-73 39. Akima H, Takahashi H, Kuno SY, Masuda K, Masuda T, Shimojo H, Anno I, Itai Y, Katsuta S. Early phase adaptations of muscle use and strength to isokinetic training. Med Sci Sports Exerc. 1999; 31: 588-94. 
40. Sandvei M, Jeppesen PB, Støen L, Litleskare S, Johansen E, Stensrud T, Enoksen E, Hautala A, Martinmäki K, Kinnunen H, Tulppo M, Jensen J. Sprint interval running increases insulin sensitivity in young healthy subjects. Arch Physiol Biochem. 2012; 118: $139-47$

41. Kavaliauskas M, Aspe RR, Babraj J. High-Intensity Cycling Training: The Effect of Work-to-Rest Intervals on Running Performance Measures. J Strength Cond Res. 2015; 29: 2229-36.

42. Jakeman J, Adamson S, Babraj J. Extremely short duration high-intensity training substantially improves endurance performance in triathletes. Appl Physiol Nutr Metab. 2012; 37: $976-81$

\section{TITLES OF TABLES}

Table 1.- Absolute changes in performance outcomes in the control and UST groups.

Table 2. - Percentage changes in performance outcomes in the control and UST groups. 
Table 1.- Absolute changes in performance outcomes in the control and UST groups.

\begin{tabular}{|c|c|c|c|c|c|c|}
\hline & \multicolumn{3}{|c|}{ CONTROL } & \multicolumn{3}{|c|}{ UST } \\
\hline & Pre & Post & $d$ & Pre & Post & $d$ \\
\hline $\begin{array}{l}\text { 5-10-5 agility } \\
\text { (s) }\end{array}$ & $6.02 \pm 0.14$ & $6.03 \pm 0.14$ & -0.2 & $5.96 \pm 0.16$ & $5.77 \pm 0.23^{\mathrm{a}}$ & 1.3 \\
\hline $\begin{array}{l}\text { Leg \& back } \\
\text { dynamometer } \\
\text { (kg) }\end{array}$ & $131 \pm 16$ & $131 \pm 23$ & 0.0 & $127 \pm 10$ & $139 \pm 11^{\mathrm{a}}$ & -3.2 \\
\hline $\begin{array}{l}\text { YO-YO R1 test } \\
\text { (m) }\end{array}$ & $\begin{array}{c}1164 \pm \\
438\end{array}$ & $1171 \pm 433$ & -0.1 & $1468 \pm 409$ & $1643 \pm 382^{a}$ & -1.5 \\
\hline $\begin{array}{l}\text { YO-YO R1 test } \\
\left(\mathrm{ml} \cdot \mathrm{kg}^{-1} \cdot \mathrm{min}^{-1}\right)\end{array}$ & $46.2 \pm 3.7$ & $46.2 \pm 3.7$ & 0.0 & $48.8 \pm 3.4$ & $50.2 \pm 3.2^{a}$ & -1.4 \\
\hline $\begin{array}{l}\text { 3km time trial } \\
\text { (s) }\end{array}$ & $\begin{array}{c}1063 \pm \\
127\end{array}$ & $1046 \pm 113$ & 0.3 & $872 \pm 70$ & $835 \pm 54^{\mathrm{a}}$ & 1.3 \\
\hline
\end{tabular}

${ }^{\mathrm{a}}=\mathrm{p}<0.05$ pre versus post; $d=$ within group cohen's $d$ effect size 
Table 2. - Percentage changes in performance outcomes in the control and UST groups.

\begin{tabular}{cccc}
\hline & $\begin{array}{c}\text { CONTROL } \\
\text { \% change }\end{array}$ & $\begin{array}{c}\text { UST } \\
\text { \% change }\end{array}$ & $d$ \\
\hline $\begin{array}{c}\text { 5-10-5 agility } \\
\text { Leg \& back }\end{array}$ & $-0.1 \pm 0.8$ & $3.2 \pm 3.3^{\mathrm{a}}$ & -1.4 \\
dynamometer & $1.9 \pm 4.9$ & $-10.4 \pm 9.6^{\mathrm{a}}$ & 0.7 \\
$\begin{array}{c}\text { YO-YO R1 test } \\
\text { distance }\end{array}$ & $-1.2 \pm 5.5$ & $-13.4 \pm 8.8^{\mathrm{a}}$ & 0.4 \\
$\begin{array}{c}\text { YO-YO R1 test } \\
\text { VO max }\end{array}$ & $-0.1 \pm 0.9$ & $-2.9 \pm 2.0^{\mathrm{a}}$ & 0.4 \\
3km time trial & $1.3 \pm 4.6$ & $4.2 \pm 3.4^{\mathrm{a}}$ & -0.2 \\
\hline
\end{tabular}

${ }^{\mathrm{a}}=\mathrm{p}<0.05$ UST compared to control; $d=$ between groups Cohen's d effect size 